\title{
Terceira Vara da Infância e da Juventude de Porto Alegre: um estudo da aplicação da análise administrativa na modernização do Estado*
}

\author{
Silvia Generali da Costa**
}

SumÁRIO: 1. Introdução; 2. Metodologia; 3. A aplicação da ferramenta; 4. Mudança de layout; 5. Quadro de distribuição do trabalho; 6. Sistemas de informações; 7. Padronização de processos; 8. Formulários e manuais; 9. Mudança organizacional; 10. Resultados imediatos; 11. Situação atual; 12. Conclusões.

S U M M A R Y : 1. Introduction; 2. Methodology; 3. Using the tool; 4. Layout change; 5. Task distribution chart; 6 . Information systems; 7. Process standardization; 8. Forms and guides; 9. Organizational change; 10 . Immediate results; 11 . Current situation; 12. Conclusions.

P AL A VR A S - C H A VE : análise administrativa; qualidade; gestão pública; modernização.

KEY WORDS: administrative analysis; quality; public management; modernization.

Este artigo descreve a experiência de aplicação da ferramenta de análise administrativa na modernização da gestão pública, especificamente na Terceira Vara da Infância e da Juventude da Comarca de Porto Alegre (RS). Foi realizada uma pesquisa-ação, com os objetivos de qualificar os procedimentos de gestão; agilizar o atendimento aos clientes e padronizar os principais processos administrativos, com vistas à futura municipalização do atendimento das medidas socioeducativas de meio aberto. A realização dos trabalhos sugeriu que, apesar das estruturas estatais fortemente burocráticas, é possível fazer uso de técnicas de racionalização de pro-

* Artigo recebido em jan. 2004 e aceito em out. 2005.

** Professora adjunta da Escola de Administração da UFRGS. Doutora e mestre em administração (PPGA/UFRGS), psicóloga (PUC-RS). Endereço: Rua Washington Luiz, 855 — Centro — CEP 90010460, Porto Alegre, RS, Brasil. E-mail: sgcosta@ea.ufrgs.br. 
cessos administrativos em setores específicos do Estado, com resultados significativos para os usuários do sistema e com baixo custo de implantação.

3rd Infancy and Youth Judgeship of Porto Alegre (Brazil): a study on the use of administrative analysis in State modernization

This paper describes the experience of applying the administrative analysis tool to the modernization of public management, more specifically at the 3rd Infancy and Youth Judgeship of Porto Alegre, Brazil. An action-survey was carried with the following goals: to qualify management procedures; to provide more effective service to clients; to standardize the main administrative processes, aiming at the future municipalization of the socio-educational measures to be applied with open sentencing. The experience has suggested that, in spite of strongly bureaucratized state structures, it is possible to employ rationalization techniques for administrative processes in specific sectors of the State, with relevant results for users of the system and a low implementation cost.

\section{Introdução}

(...) o tipo de governo que se desenvolveu durante a era industrial, com suas burocracias lentas e centralizadas, preocupado com normas e regulamentos, sujeito a cadeias de comando hierárquicas, deixou de funcionar bem. Na sua época esses governos foram capazes de grandes realizações, mas ao longo do tempo se afastaram das nossas necessidades. Tornaramse inchados, ineficientes, funcionando com desperdício. E quando o mundo começou a mudar, não acompanharam essas mudanças.

As burocracias hierárquicas, centralizadas, concebidas nas décadas de 1930 e 1940, simplesmente não funcionam bem no quadro altamente mutável da sociedade e da economia dos anos 1990, rico de informações e conhecimento. São como transatlânticos de luxo numa era de jatos supersônicos: grandes, caros e pouco ágeis. Gradualmente estão sendo substituídos por novas modalidades de instituições públicas.

Osborne e Gaebler (1998:12-13)

As idéias expressas na citação acima não são exclusivas de Osborne e Gaebler. Uma série de autores tem questionado o esgotamento do modelo burocrático público, diante das rápidas mudanças nos âmbitos tecnológico, político, econômico, social e tributário, levando à incapacidade das instituições governamentais em atender de forma satisfatória às demandas crescentes da sociedade. Para superar as limitações do modelo burocrático, sugere-se desde a aplicação de modelos de gerenciamento 
até então exclusivos da iniciativa privada (Brown e Brudney, 2003; Vieira, 2003; Marini, 2002; R. Oliveira, 2002; Garces e Silveira, 2002; Rosenberg e Ohayon, 2002; Feldman e Khademian, 2002; Dinsdale et al., 2000) até a adoção do espírito empreendedor na condução das instituições públicas, incluindo reduções de quadro funcional e privatizações (Pacheco, 2002; Osborne e Gaebler, 1998). Questiona-se quem é o cliente do setor público (Costa, 2003; Alford, 2002), quem deseja atendêlo, e por quê (Lewis e Frank, 2002).

Neste contexto, insere-se a pesquisa na Terceira Vara. Havia o reconhecimento de que a clientela apresentava uma gama de necessidades específicas e variadas, que não poderiam ser contempladas através de um modelo de gestão único e inflexível. Havia ainda uma genuína motivação para a mudança, de parte da liderança do projeto, que vislumbrava um modelo de gestão sistêmica, com a inserção da Terceira Vara numa ampla rede interinstitucional de atendimento ao adolescente autor de ato infracional ou em situação de risco social.

Assim, o artigo teve como foco inicial as instituições diretamente envolvidas na rede de atendimento e a aplicação de ferramentas modernas de gestão na condução dos trabalhos, apesar da permanência do modelo burocrático na instituição como um todo (Foro Central, de forma restrita, e Poder Judiciário estadual, de forma mais ampla). A seguir, apresenta-se uma breve introdução sobre a situação problemática e a caracterização dos ambientes interno e externo.

A Terceira Vara da Infância e da Juventude da Comarca de Porto Alegre pertence ao Foro Central da capital e era, por ocasião da realização da pesquisa, responsável pelo atendimento técnico e jurisdicional de adolescentes autores de ato infracional. Pela Terceira Vara tramitam, ainda hoje, dois tipos de processos: os relativos à execução de medidas socioeducativas ditas “de meio aberto”, em que os adolescentes não estão recolhidos a nenhuma instituição privativa de liberdade; e os chamados "de meio fechado", onde os adolescentes estão recolhidos a unidades da Fundação de Atendimento Sócio-Educativo (Fase), antiga Fundação Estadual de Bem-Estar do Menor (Febem). Na Terceira Vara são atendidos todos os trâmites jurídicos referentes aos processos de ato infracional, como audiências de progressão ou de regressão de medidas; tramitação cartorária, julgamentos e sentenças; assim como eram atendidas na ocasião todas as questões técnicas, como a avaliação psicológica e psiquiátrica dos adolescentes, o acompanhamento socioeducativo especializado e o acompanhamento do cumprimento da medida socioeducativa aplicada. Atualmente, o atendimento técnico encontra-se municipalizado.

Em 1997, portanto no ano anterior ao do início da pesquisa, a vara contava com 20 técnicos na área social, sendo dois estatutários e 18 celetistas. Na área cartorária, o número de servidores também se aproximava de duas dezenas. O número de processos havia aumentado de forma significativa. Se em dezembro de 1996 contabilizavam-se 884 processos de meio aberto, em dezembro de 1997 os números saltaram para 1.473. ${ }^{1}$ Paralelamente à questão do volume processual, observava-se o 
agravamento dos tipos de delito, indicando a necessidade de novos tipos de intervenção socioeducativa, de caráter mais abrangente e sistêmico.

Como em todo o Foro Central, onde as varas são geridas pelos juízes designados, a Terceira Vara é administrada por um juiz de direito, apoiado fortemente, na condução do cartório, pelo escrivão. A equipe técnica não conta com um gestor que corresponda à figura do escrivão, sendo administrada diretamente pelo juiz.

Em 1998, iniciou-se um amplo processo de reconfiguração da execução das medidas socioeducativas, em consonância com o Estatuto da Criança e do Adolescente (ECA), Lei n⿳0 8.069/90 (Brasil, s.d.), em seus princípios de descentralização administrativa, construção democrático-participativa, articulação em rede e gestão sistêmica, desjudicialização, municipalização e integração do atendimento aos adolescentes em conflito com a lei (Silveira e Aguinsky, 2003; Brancher, 1998; Brancher e Costa, 1998).

A Terceira Vara, que havia iniciado suas atividades há mais de 60 anos, como o antigo Juizado de Menores, vinha passando por uma série de reformulações, com o objetivo de atender à demanda crescente. Essas reformulações, no entanto, não foram suficientes do ponto de vista gerencial em face da escassez de recursos financeiros e materiais com a qual se defrontava. Clientes externos (adolescentes em conflito com a lei) e internos (magistrados e servidores) pareciam insatisfeitos. Brancher e Costa (1998:8), referindo-se ao ano de 1988, relatam: "Para que se tenha idéia da complexidade do problema, já há quatro anos, um relatório da equipe de Liberdade Assistida dava conta de que era impossível continuar trabalhando com a então relação de técnicos por processo, que era de 1 para cada 40. Hoje essa relação é de 1 para cada 90”.

Do ponto de vista do atendimento ao cliente externo, foram identificadas as seguintes necessidades: "tendência crescente à desordem e violência entre adolescentes, tendência crescente à maior gravidade nas infrações (estupros, homicídios, latrocínios) diante da insuficiente resposta às de menor gravidade, inviabilidade do modelo de concentração judicial em satisfazer a demanda” (Brancher, Silveira e Costa, 1999:2).

Assim, o projeto mais amplo de reconfiguração do sistema pretendia articular uma rede pública de atendimento à criança e ao adolescente, diminuir os índices de violência e de criminalidade entre adolescentes, e criar condições para atuação em foros específicos, como, por exemplo, a violência nas escolas. Os objetivos estendiam-se da esfera política, com a redefinição dos papéis do Poder Executivo estadual e

\footnotetext{
1 Nos anos seguintes, os números mantiveram-se mais estáveis: 1.506 em dezembro de 1998, 1.278 em dezembro de 1999, 1.325 em dezembro de 2000, 1.453 em dezembro de 2001, 1.416 em dezembro de 2002 e 1.476 em novembro de 2003. Os dados referentes a dezembro de 2003 não estavam disponíveis em 30 de dezembro. Todos os números são referentes a processos de meio aberto, ou seja, sem privação de liberdade. As informações foram prestadas pelo cartório da Terceira Vara da Infância e da Juventude de Porto Alegre, por consulta ao Sistema JIJ — Mapa Estatístico.
} 
municipal na execução do atendimento ao adolescente autor de ato infracional e com a transferência do atendimento socioeducativo ao município, até a esfera operacional, com a descentralização geográfica do atendimento e a formação de uma rede de atendimento socioeducativo, ou seja, a criação de um sistema de atenção ao adolescente infrator em rede (Brancher, Silveira e Costa, 1999).

Este contexto ensejou a aplicação de ferramentas gerenciais, com o intuito de preparar administrativamente a vara para o processo de desjudicialização e municipalização das medidas socioeducativas de meio aberto, e responder à crescente demanda.

\section{Metodologia}

Foi realizada uma pesquisa-ação, considerada uma pesquisa de base empírica, com o "envolvimento dos pesquisadores e dos pesquisados no processo de pesquisa" (Gil, 1999:47). O critério de escolha da população foi de acessibilidade e de demanda por parte da instituição pesquisada. O trabalho foi realizado entre os anos de 1998 e 1999, sendo que em 2003 foram aferidos os resultados de médio prazo das intervenções realizadas, com entrevistas não-estruturadas com os gestores locais e consultas a documentos internos.

\section{A aplicação da ferramenta}

\section{Sensibilização}

Sensibilizar é tornar o indivíduo integrante de um processo de mudança, é permitir o sim e o não, a crença e a descrença. É fazêlo entender as razões e os porquês da mudança.

Araújo (2001:40)

Diante das dificuldades observadas no atendimento ao cliente e em face do desafio da municipalização do atendimento das medidas socioeducativas de meio aberto, tornou-se necessário buscar a adesão em torno de um amplo projeto de mudança organizacional. Iniciou-se uma série de reuniões de integração e de discussão das reformas, onde os objetivos do trabalho que se iniciava eram apresentados, debatidos e analisados. Durante as reuniões, foram utilizados textos, filmes e técnicas de dinâmicas de grupo. Procurou-se integrar os membros da equipe, que até o momento atuavam divididos em áreas e equipes estanques e com comunicação deficiente. Também foi objetivo das reuniões dirimir dúvidas e enfraquecer resistências ao projeto, visto que a adesão e o comprometimento de todos era essencial para 
o seu sucesso. Finalmente, a sensibilização era apenas o início de uma grande tentativa de mudança na cultura organizacional.

As reuniões foram todas presididas pessoalmente pelo líder da área, no caso, o magistrado responsável pela vara, denotando envolvimento da liderança no processo desde seu início. O estilo informal adotado contribuiu para a criação de um clima favorável à realização dos trabalhos.

Naturalmente, as reuniões de sensibilização não eliminaram todas as resistências, dúvidas e questionamentos. Como disse Araújo (2001:40), “(...) haverá dificuldades, à medida que o estudo tiver conotações traumatizantes. De qualquer maneira, menor será o grau de dificuldade, se houver uma reunião esclarecedora que sensibilize o grupo objeto de mudança”. No caso desse projeto, considerando o grau de impacto das mudanças pretendidas sobre a rotina dos membros da unidade, já era esperado um alto grau de dificuldade. Apesar disso, as dificuldades encontradas superaram as mais pessimistas expectativas. A falta de recursos materiais e logísticos, a franca resistência ao projeto e o engessamento provocado pela estrutura burocrática vigente foram alguns dos destaques. A seguir serão comentadas as dificuldades mais significativas.

\section{A ferramenta análise administrativa e a qualidade total}

Considerando que o Tribunal de Justiça do Estado do Rio Grande do Sul conta com o Programa de Gestão pela Qualidade do Judiciário (PGQJ), optou-se por realizar a análise administrativa e implantar os projetos de mudança dentro da metodologia da qualidade e com o apoio de consultores da área, tanto internos como externos. Assim, os cursos realizados foram promovidos internamente, da mesma forma que foram desenhados os macrofluxos, os fluxogramas, os manuais e formulários, estes com a consultoria de assessores externos indicados pelo PGQJ. ${ }^{2}$

Entre os cursos e programas oferecidos, destacam-se:

5S: a arrumação geral — Aproveitando a futura mudança de layout e localização das salas, optou-se por realizar uma arrumação geral, a partir dos critérios do 5S metodologia da qualidade. Móveis quebrados e papéis inúteis foram descartados, armários e gavetas arrumados, houve uma nova disposição dos equipamentos para café e foram colocados quadros, vasos de flores e alguns objetos de decoração. Importante ressaltar que a desorganização já havia sido incorporada ao dia-a-dia dos servidores, não sendo mais percebida como tal, evidenciando-se o fenômeno de "filtragem seleti-

\footnotetext{
${ }^{2}$ Os consultores externos contratados foram Plínio Fonseca e Sérgio Boaz, coordenados pelo juiz de direito dr. Leoberto Narciso Brancher.
} 
va” (Schermerhorn, Hunt e Osborn, 1999) ou “percepção seletiva” (Robbins, 1999). Caixas de papelão jaziam nos corredores sem serem retiradas, enquanto servidores “saltavam” os obstáculos encontrados. A arrumação geral teve o mérito de alertar a equipe sobre fatos que causariam estranheza aos visitantes, mas que soavam naturais aos funcionários.

Cursos comportamentais e técnicos — Em paralelo às mudanças administrativas, foram levados a termo cursos nas áreas técnica e comportamental. Entre os cursos oferecidos aos servidores estavam microinformática; noções básicas e ferramentas de qualidade, incluindo qualidade em serviços, gestão da qualidade total e desenvolvimento comportamental para a qualidade; integração de equipes; relacionamento interpessoal, entre outros. O enfoque técnico foi necessário principalmente na capacitação ao uso de ferramentas de microinformática, antes inexistentes na vara, e na qualificação no uso de ferramentas da qualidade, como espinha de peixe, Masp, desenho e análise de fluxogramas, entre outras.

Já o enfoque comportamental mostrou-se indispensável devido aos conflitos existentes entre equipes e entre técnicos, e à compartimentalização de atividades e funções imposta pelo modelo burocrático de gestão vigente. Para tanto, foram desenvolvidas diversas sessões de dinâmica de grupo, com especialistas na área comportamental.

Cabe ressaltar, aqui, a utilização do conceito de qualidade com enfoque no serviço público. Ao contrário de Araújo (2001:211), que destaca que a qualidade é “(...) a busca pela perfeição com a finalidade de agradar clientes cada vez mais conscientes das facilidades de consumo e variedades de empresas a oferecer produtos”, não considerou-se a questão de lucratividade e competitividade. $\mathrm{O}$ enfoque dado à análise aplicada foi de aperfeiçoar o atendimento ao cliente interno e externo.

\section{Mudança de layout}

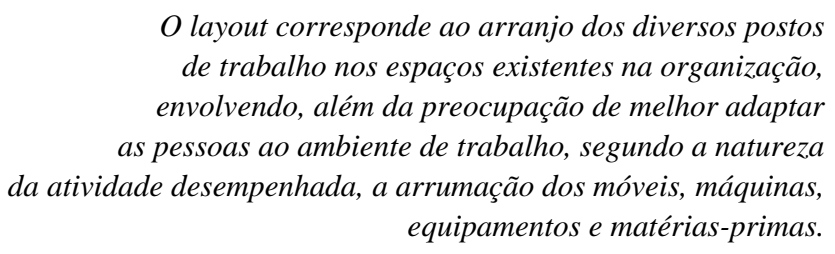

Cury (2000:386)

A Terceira Vara da Infância e da Juventude está situada no $10^{\underline{0}}$ andar do Foro Central de Porto Alegre. Na fase anterior aos trabalhos, a área técnica localizava-se em 
posição diametralmente oposta à área cartorária e à sala do magistrado titular. Em outras palavras, as duas áreas ficavam em extremos opostos de um corredor de aproximadamente 50 metros. Como resultado, cada vez que técnicos e oficiais de cartório necessitavam trocar informações sobre processos, uma grande distância era percorrida. Não raro, o técnico procurado ou o processo não estavam disponíveis, fazendo com que os servidores refizessem o percurso várias vezes até atingirem seus objetivos ou ainda, o que era pior, acabassem desistindo de fazer determinada consulta.

Paralelo a isso, havia na equipe técnica três salas distintas: a de atendimento da medida de liberdade assistida (LA), a de atendimento da medida de prestação de serviços à comunidade (PSC) e a de avaliação psicológica e psiquiá-trica (Perícia). Ocorre que diversos adolescentes recebiam mais de uma medida, sendo obrigados a "passar de sala em sala” e contar sua história a dois ou três técnicos diferentes, que não trocavam informações entre si. Nesse contexto, foram observados episódios de adolescentes evadidos do programa sendo conduzidos ao Foro Central pelos oficiais de proteção para apresentação ao acompanhamento de LA, não se apresentando ao acompanhamento de PSC. A falta de comunicação entre os técnicos tornava necessário, nesses casos, acionar novamente a equipe de oficiais de proteção, com prejuízos ao Estado.

As mudanças no layout começaram por aproximar área técnica, cartório e magistrado, dispostos em salas contíguas, separadas por divisórias. No caso do cartório e da equipe técnica, apenas um pequeno corredor de aproximadamente dois metros separava os servidores. Com isso, a comunicação passou a fluir com maior eficiência e rapidez.

A segunda providência foi a de integrar as três equipes técnicas numa sala única (LA, PSC e Perícia) com redefinição de suas atribuições. Este aspecto será descrito detalhadamente a seguir.

Assim, procurou-se atender aos objetivos de um projeto de layout tal como propostos por Cury (2000): otimizar as condições de trabalho, racionalizar os fluxos de tramitação de processos, aproveitar o espaço disponível e minimizar a movimentação de pessoas, produtos, materiais e documentos.

\section{Quadro de distribuição do trabalho}

No que se refere à distribuição do trabalho, a pesquisa buscou atingir, prioritariamente, dois dos objetivos propostos por D. Oliveira (2002:344): “redistribuir, de forma criteriosa e racional, as tarefas que já vêm sendo realizadas pela empresa; e funcionar como instrumento de estudo da situação existente e de mudança para a situação desejada, quando da racionalização organizacional”. 
A análise da distribuição do trabalho indicou uma disparidade no volume de trabalho de cada equipe. Embora os processos de LA e PSC se assemelhassem em quantidade, possuíam características intrínsecas diferentes, o que resultava demandas distintas aos técnicos envolvidos. Os de PSC são finalizados com maior rapidez, visto a medida aplicada geralmente ter a duração de um a três meses, além de ser destinada a casos de menor gravidade. Já os de LA têm a duração média de seis meses e são aplicados a situações mais graves, com maior incidência de evasão do programa, reincidência em delitos e outras ocorrências que retardam o atendimento socioeducativo. Diferente da LA e da PSC, as indicações de perícia são mais eventuais, gerando uma menor demanda de trabalho aos técnicos.

Considerando, então, os diferentes volumes de trabalho e o fato anteriormente citado de que os adolescentes podem receber mais de uma medida, optou-se por integrar as equipes, inicialmente as de PSC e LA. Com isso, houve melhor distribuição do volume de trabalho e eliminaram-se as possíveis dissociações no atendimento. Os adolescentes passaram a ser trabalhados com foco no indivíduo e não na medida recebida, de forma integral e sistêmica. O novo sistema possibilitou que cada técnico desenvolvesse uma relação mais próxima e profunda com os adolescentes atendidos, favorecendo a criação dos vínculos tão necessários ao processo de reinserção social. Eliminou-se, assim, a impessoalidade burocrática, que tratava cada adolescente como um elemento estanque, sem considerar sua história de vida, suas motivações, necessidades e especificidades.

\section{Sistemas de informações}

Nessa fase da pesquisa, utilizou-se o conceito proposto por D. Oliveira (2002:51):

\footnotetext{
Sistema de informações é o processo de transformação de dados em informações. E, quando esse processo está voltado para a geração de informações que são necessárias e utilizadas no processo decisório da empresa, diz-se que esse sistema é um sistema de informações gerenciais.
}

Para a criação de um embrião de um futuro sistema de informações gerenciais, um longo caminho teve de ser percorrido. No início do processo, não havia microcomputadores na vara. Os técnicos faziam seus relatos de atendimento manualmente. Os registros dos dados dos adolescentes atendidos, bem como qualquer tipo de consulta sobre seus casos, eram feitos em papel, gerando dificuldade de organização, lentidão no acesso aos dados e no registro dos resultados do acompanhamento, além de visão fragmentada do sistema. Logo se percebeu a necessidade de informatizar a área. Buscou-se então parceria com a iniciativa privada, dada a não-provisão de recursos no orçamento do Judiciário para o ano corrente relativa a equipamentos e softwares. O Grupo Gerdau 
respondeu prontamente à solicitação, interessado em apoiar a modernização do Estado. Além de doar microcomputadores usados, a empresa cedeu horas de trabalho de seus próprios técnicos para instalação dos equipamentos e para o treinamento dos servidores na utilização dos programas. Foi desenvolvido um sistema no qual cada adolescente possui uma página de registro de todo o histórico de atendimento, de julgamentos e de tramitação do processo. Todos os técnicos têm acesso e alimentam a "pasta eletrônica" do adolescente, integrando e qualificando o atendimento. Com a disponibilização dos computadores, os formulários padronizados e desenvolvidos a partir da análise administrativa foram colocados em rede, agilizando a consulta às informações.

Os resultados não constituíram um sistema de informações gerenciais propriamente dito, mas os primeiros passos foram dados e o trabalho ganhou em qualidade e rapidez.

\section{Padronização de processos}

Tachizawa e Scaico (1997) identificam seis etapas na metodologia de padronização de processos: identificar os processos-chave, estabelecendo o fluxo básico e o macrofluxograma; elaborar e analisar a matriz de responsabilidades; definir os indicadores de qualidade; elaborar o procedimento operacional; desenvolver o treinamento conforme o procedimento operacional e auditar a operacionalização do processo.

Alguns desses passos sugeridos pelos autores foram realizados durante a pesquisa na Terceira Vara. Discutiu-se e definiu-se a estrutura do sistema, com a indicação dos principais fornecedores, insumos, recursos, produtos e clientes da vara. A seguir, foi elaborado o macrofluxo do processo de execução de medidas socioeducativas, a principal atribuição da Terceira Vara.

Após o macrofluxo, foram desenhados os fluxogramas dos principais processos, considerando o conceito de D’Ascenção (2001:110), que caracteriza fluxograma como "uma técnica de representação gráfica que se utiliza de símbolos previamente convencionados, permitindo a descrição clara e precisa do fluxo, ou seqüência, de um processo, bem como sua análise e redesenho”.

Do trabalho, resultaram os fluxogramas de avaliação social, psicológica e psiquiátrica; processo judicial com documentos juntados; informações e encaminhamentos (atendimento no balcão); tramitação processual das medidas de meio aberto; tramitação processual das medidas de meio fechado; e orientação socioeducativa.

Finalmente, foram elaborados os procedimentos operacionais (PO), “(...) um tipo de padrão voltado para a tarefa (...) destina-se a fixar condições para a execução de quaisquer operações de conteúdo técnico e administrativo” (Tachizawa e Scaico, 1997:144).

O processo de análise, definição e padronização de procedimentos possibilitou o treinamento de novos funcionários e a simplificação e racionalização das rotinas. Além disso, significou um repensar sobre o próprio modelo burocrático, um modelo que se caracteriza pelo seu apego a regras e padrões obsoletos e 
desnecessários, “(...) um sistema de organização incapaz de corrigir-se em função de seus erros, e cujas disfunções se convertem em um dos elementos essenciais de seu equilíbrio” (Crozier apud Ramos, 1966:251).

\section{Formulários e manuais}

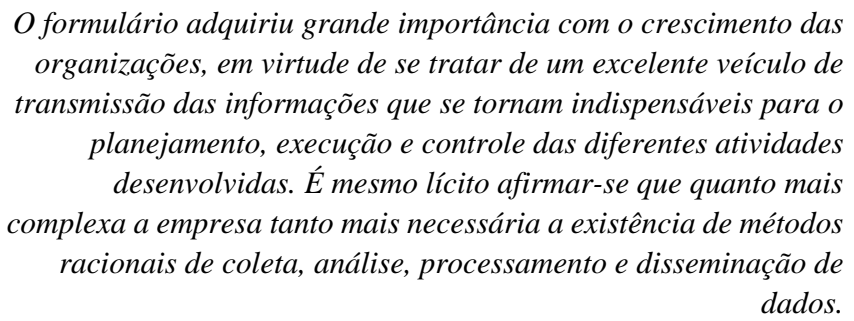

Addison (apud Cury, 2000:361)

No início dos trabalhos não havia um padrão único para os relatórios de acompanhamento, nem no que se referia a prazos de entrega, nem ao conteúdo. Os formulários desenvolvidos representaram não apenas a formalização de procedimentos usuais, mas sua revisão e aprimoramento, com a inclusão de etapas no processo de atendimento, anteriormente inexistentes. É o caso do Plano de Atendimento, novo padrão desenvolvido, que representou uma inovação nos métodos de trabalho.

Foram criados os formulários: Informação, dando conta sobre o comparecimento ou não do adolescente a uma audiência admonitória coletiva, início de todo o processo de atendimento; Guia de Inclusão do adolescente no sistema de Justiça e no Programa Socioeducativo; Plano de Atendimento, onde o técnico descreve a situação atual do adolescente, os objetivos do atendimento socioeducativo para aquele caso específico, os atendimentos previstos e os encaminhamentos propostos; Acompanhamento de Freqüência em Liberdade Assistida; Relatório Bimestral de Atendimento, mostrando os resultados parciais dos esforços técnicos na reinserção social dos adolescentes; Relatório de Ocorrência, onde o técnico registra incidentes no atendimento, tais como evasão do programa, novas infrações e sentenças, evasão da escola, conflitos com o técnico, abandono do lar, necessidade de internação hospitalar, de recolhimento a abrigo etc.; Histórico da Execução, com todos os passos seguidos pelo adolescente desde a inclusão no programa até o encerramento da medida socioeducativa; e Relatório Conclusivo, onde são registrados os resultados do atendimento.

Além desses formulários, foram desenvolvidos outros para uso interinstitucional, como Solicitação e Confirmação de Atendimento; Confirmação de Início de Cumprimento da PSC; Acompanhamento de Freqüência da PSC; Advertência, em caso de descumprimento ou indisciplina; Solicitação de Substituição de Unidade de Execução de 
Medida, para os que não se adaptam ao local de cumprimento da PSC; Comunicação de Evasão; Relatório de Acompanhamento de Atendimento Institucional, para os adolescentes encaminhados às diversas instituições da rede de atendimento; e Relatório Conclusivo da PSC, além de outros de uso, controle e expedição cartorária, para registrar os movimentos Terceira Vara — Fase. Atualmente, todos os formulários estão disponíveis na rede e contam com instruções de preenchimento relativas a cada campo definido.

\title{
9. Mudança organizacional
}

\begin{abstract}
Conceituamos mudança organizacional como qualquer alteração significativa, articulada, planejada e operacionalizada por pessoal interno e/ou externo à organização que tenha o apoio e a supervisão da administração superior e atinja, integradamente, os componentes de cunho comportamental, estrutural, tecnológico e estratégico.
\end{abstract}

Araújo (2001:254)

Como em todo processo de mudança organizacional, encontraram-se resistências e dificuldades. O ritmo de implantação das mudanças foi bastante acelerado, e à sobrecarga habitual de tarefas da vara somou-se o volume de trabalho imposto pela revisão dos processos administrativos existentes, com as necessárias reuniões, providências e demandas extraordinárias. Além disso, a redistribuição da carga de trabalho certamente não agradou a todos, sobretudo aos que tiveram seus ritmos de trabalho alterados para mais.

Elementos culturais somaram-se às dificuldades mais comuns. Muitos servidores já haviam passado por diversos processos de mudança e acreditavam que, ao final, as atividades não trariam resultados duradouros nem proveitosos para as equipes. Em outras palavras, testemunharam que as mudanças beneficiariam apenas a instituição, que os servidores ficariam mais sobrecarregados e sob controle mais cerrado da administração, perdendo em liberdade sobre seu modus operandi, muito próprio e consolidado. Frases como "vamos mudar tudo para não mudar nada” e "a mudança vai durar enquanto durar o juiz” foram ouvidas durante a realização da pesquisa.

É natural que, como em toda a mudança organizacional, houvesse também os entusiastas, principalmente entre os que viam vantagens na transição, como aqueles que puderam compartilhar com os colegas uma carga de trabalho desproporcional.

Na promoção e consolidação da mudança, a liderança exerceu um papel fundamental, destacando-se o trabalho de identificação e desenvolvimento de potenciais e de formação de uma equipe informal de staff, ligada ao projeto. 
O líder do projeto procurou, de imediato, cercar-se de elementos motivados, qualificados e alinhados em torno do projeto da proposta, que passaram a constituir um grupo de assessoria informal e a dedicar-se de forma mais intensiva à coordenação, acompanhamento e execução dos trabalhos. Tal estratégia permitiu, de um lado, que houvesse um grupo estável e coeso levando a termo os trabalhos e garantindo que as mudanças ocorressem dentro do escopo, do prazo e dos objetivos planejados. Ao mesmo tempo, a indicação de um staff garantiu o aproveitamento de talentos e habilidades até então subutilizados pelo esquema burocrático e, como consequiência, uma maior motivação dos membros escolhidos. De outro lado, houve problemas na adoção de tal política. Os membros do grupo não escolhidos para compor o staff tornaram-se mais reticentes ao projeto de mudança. Alguns transformaram-se em líderes negativos, disseminando idéias contrárias ao projeto de modernização e mostrando-se refratários a qualquer tentativa de envolvimento.

Esta situação está bem caracterizada na teoria da troca líder-membro (TLM). A teoria preconiza que os líderes estabelecem uma relação especial com um pequeno grupo de subordinados (o grupo de dentro), que passa a receber atenção especial. Os outros subordinados constituem o grupo de fora, e mantêm interações de caráter mais formal. A permanência no grupo de dentro ou no grupo de fora tende a se tornar estável ao longo do tempo e as atitudes de todos, líder e subordinados, tendem a reforçar os papéis predefinidos. Estudos indicam que os membros de dentro são escolhidos por possuírem características similares às características pessoais do líder, uma personalidade extrovertida e maior competência dos que os colegas do grupo de fora (Robbins, 1999).

\section{Resultados imediatos}

Resultados positivos puderam ser observados em diferentes níveis. No nível interinstitucional, evidenciou-se um incremento da integração entre as equipes da vara e as equipes da rede de atendimento (Fase, Fasc, abrigos, escolas, comunidade), possibilitando um acompanhamento mais efetivo e sistêmico dos adolescentes. No nível do sistema judiciário, observou-se a melhoria da comunicação entre os técnicos e juízes das três varas responsáveis pela infância e juventude no Foro Central de Porto Alegre. Tal melhoria é de extrema importância considerando-se que a Primeira e a Segunda Varas da Infância e da Juventude, embora não executem, também julgam processos de adolescentes envolvidos em infrações. Além disso, pode-se supor que uma parcela dessa população de adolescentes já tenha passado pelas demais varas em situações anteriores de risco social, abrigo, denúncia de maus-tratos, destituição de pátrio poder etc. Na Terceira Vara, houve uma visível e forte melhoria na integração entre as equipes técni- 
cas (unificadas a partir dos trabalhos) e a equipe cartorária, resultando, igualmente, na prestação de um atendimento mais qualificado e sistêmico.

Melhorias significativas também foram observadas nos mecanismos de gestão e de controle interno. Após a realização dos trabalhos foi possível mapear com clareza informações necessárias à tomada de decisão, tais como o número médio de processos acompanhados pelos técnicos, por medida socioeducativa; o tipo de abordagem empregada na reinserção social dos adolescentes; os elementos disponíveis na rede de atendimento; e o tempo médio de conclusão dos processos. Além disso, a padronização do atendimento e a criação dos formulários correspondentes permitiram a garantia de um padrão mínimo de atendimento, o controle dos prazos e o acompanhamento dos resultados. A vara também passou a contar com registros de suas atividades para fins de futuras pesquisas.

Em relação aos servidores, houve incremento das habilidades técnicas, principalmente relativas à informática e aplicação de ferramentas da qualidade, e a já referida integração entre indivíduos e equipes.

Um dos principais resultados observados, porém, foi a prontidão para que se efetivasse a municipalização das medidas socioeducativas de meio aberto, sem que a Terceira Vara perdesse o controle dos processos, já que a vara manteria sua função de controle e acompanhamento jurisdicional.

Dificuldades também existiram, lado a lado com as realizações. Em primeiro lugar, não se logrou êxito na constituição de um sistema integrado de informações gerenciais. Um banco de dados interinstitucional, em rede, que desse conta da passagem dos adolescentes pelas diversas instituições que compõem a rede de atendimento à infância e à juventude e que preservasse e resgatasse sua história, sempre que necessário, ainda hoje é um sonho distante. Na mesma linha, indicadores gerenciais precisos, tais como índice de reincidência dos adolescentes atendidos em cada programa, de acordo com os diferentes perfis (idade em que cometeu a infração, escolaridade, nível socioeconômico, estrutura familiar, história de vida, patologias clínicas e psicológicas etc.), de acordo com a instituição que executou o programa (no caso da PSC ou da internação) ou o acompanhamento (no caso de encaminhamento a atendimento hospitalar, ambulatorial, clínico ou psicológico), do técnico que realizou o atendimento etc., não puderam ser estabelecidos, restando como metas futuras. Naturalmente tais indicadores seriam vitais para avaliação não só do desempenho da vara, mas para obtenção de dados comparativos que indicassem o sucesso ou não da municipalização no que se refere à melhoria do atendimento aos adolescentes e aos resultados obtidos na busca de sua reinserção social.

\section{Situação atual}


Atualmente, a municipalização da execução das medidas socioeducativas de meio aberto foi concluída. O município está realizando o atendimento aos adolescentes autores de ato infracional, buscando sua reinserção social. $\mathrm{O}$ atendimento é prestado por técnicos da prefeitura em conjunto com técnicos do Poder Judiciário, deslocados para o município com a finalidade específica de repassar a tecnologia de atendimento, integrar as instituições e fazer o acompanhamento jurisdicional dos processos. Foi criado um conselho gestor, com participantes do município e do Poder Judiciário, a fim de garantir a qualidade e o acompanhamento do processo de municipalização, bem como a integração efetiva entre os poderes Judiciário estadual e Executivo municipal.

Em paralelo, efetivou-se a integração das equipes das três varas de atendimento à infância e à juventude, com a criação da equipe de ato infracional, preservando-se a especialização dos técnicos. A equipe de ato infracional, como foi chamada a nova constituição dos técnicos das três varas, passou a atuar com a metodologia de discussão de casos, dentro de uma lógica sistêmica.

O líder do projeto foi promovido para uma função que o afastou da "militância da Infância e Juventude”, nas palavras do próprio juiz. Não obstante o afastamento físico e da liderança formal do projeto, continua buscando a articulação das diversas instâncias responsáveis pelo atendimento socioeducativo, bem como procura desenvolver novas lideranças que tomem a frente nos processos de mudança.

\section{Conclusões}

Este artigo demonstrou a possibilidade da aplicação de ferramentas gerenciais na modernização do serviço público. Naturalmente, o uso isolado das ferramentas e técnicas disponíveis não garante, por si só, a desburocratização total dos serviços, já que a vara se insere numa instituição complexa, de grande porte, com características fortemente burocráticas. No entanto, foi possível observar a criação de um foco de disseminação de novas idéias no Foro Central, compartilhado por outros juízes simpatizantes do movimento pela qualidade no Poder Judiciário e por juízes inoculados pelo vírus da inovação. É também importante ressaltar os efeitos mais amplos do trabalho, cujo escopo envolveu as demais instituições que fazem interface com a Terceira Vara e que acabaram por rever alguns de seus processos a fim de acompanhar as novas demandas administrativas.

Dificuldades se apresentaram, inequivocamente. Como em todo serviço público, o grande desafio é o de continuidade dos projetos de mudança, após a saída do líder principal, o que acontece de forma cíclica e inevitável. Até que ponto a saída do juiz líder do processo de mudança afetará os resultados futuros ou implicará retrocesso ainda é precoce avaliar. Há, entretanto, fortes indícios de que, mesmo ha- 
vendo retrocessos, alguns ganhos estarão consolidados, como a integração das equipes e a redefinição de seus papéis.

Outra dificuldade a destacar foi a resistência ativa e organizada de alguns grupos cujos interesses foram fortemente afetados. A resistência foi de tal ordem que gerou um dilema: até que ponto é possível implantar um processo de mudança totalmente participativo, com base no comprometimento, ou até que ponto medidas de controle e de punição devem ser adotadas? Drucker (1997) já levantava a problemática da implantação de estruturas orgânicas, flexíveis e participativas, em relação às dificuldades de controle, que parecem pertencer ao paradigma do fayolismo e tender à obsolescência. Os debates sobre liderança também buscam resposta ao dilema "liderança democrática versus controle” sugerindo que eventualmente estilos de liderança autocráticos são necessários, dependendo do nível de maturidade dos subordinados (Hersey e Blanchard, 1986) ou que jamais devem ser utilizados (O’Toole, 1997). Independente das discussões acadêmicas, a possibilidade de emprego de um sistema de punições e recompensas e de aumento do controle sobre o pessoal não é de livre-arbítrio do líder do projeto, dependendo de outras instâncias que podem inviabilizar a aplicação de tratamentos distintos a indivíduos diferentes, característica marcante da administração pública.

Finalmente, o artigo sugere que microações (não se “reinventa o governo", como pretendem Osborne e Gaebler, mas se racionalizam processos) podem ser desejáveis, de baixo custo para o Estado e de resultados notáveis no dia-a-dia das equipes e do atendimento ao usuário.

\section{Referências bibliográficas}

ALFORD, John. Defining the client in the public sector: a social-exchange perspective. Public Administration Review, v. 62, n. 3, May/June 2002.

ARAÚJO, Luis César G. de. Organização, sistemas e métodos e as modernas ferramentas de gestão organizacional: arquitetura, benchmarking, empowerment, gestão pela qualidade total, reengenharia. São Paulo: Atlas, 2001.

BRANCHER, L. N. Reconfiguração do sistema de Justiça da Infância e da Juventude na execução de medidas sócio-educativas. Porto Alegre: Poder Judiciário do Estado do Rio Grande do Sul, 1998. (Relatório Técnico da 3aㅡ Vara JIJ).

; COSTA, S. G. Visão sistêmica da implementação e da gestão da rede de atendimento projetada pelo Estatuto da Criança e do Adolescente. Porto Alegre: Poder Judiciário do Estado do Rio Grande do Sul, 1998. (Relatório Técnico da 3aㅡ Vara JIJ). 
; SILVEIRA, A. E. L.; COSTA, S. G. Desjudicialização e municipalização do atendimento na execução das medidas sócio-educativas de meio aberto: esboço para discussão. Porto Alegre: Poder Judiciário do Estado do Rio Grande do Sul, 1999. (Relatório Técnico da 3ª̣ Vara JIJ).

BRASIL. Lei Federal no 8.069/1990, de 13 de julho de 1990. Dispõe sobre o Estatuto da Criança e do Adolescente e dá outras providências. Organização da Secretaria do Trabalho, Cidadania e Assistência Social do Rio Grande do Sul e do Conselho Estadual dos Direitos da Criança e do Adolescente — Cedica, Porto Alegre, s.d.

BROWN, Mary Maureen; BRUDNEY, Jeffrey L. Learning organizations in the public sector? A study of police agencies employing information and technology to advance knowledge. Public Administration Review, v. 63, n. 1, Jan./Feb. 2003.

COSTA, Silvia Generali. Gestão pública em debate. Administração no Milênio, v. 2, n. 4, Inverno 2003.

CURY, Antonio. Organização e métodos: uma visão holística. 7. ed. São Paulo: Atlas, 2000.

D’ASCENÇÃO, Luiz Carlos M. Organização, sistemas e métodos: análise, redesenho e informatização de processos administrativos. São Paulo: Atlas, 2001.

DINSDALE, Geoff et al. Metodologia para medir a satisfação do usuário no Canadá: desfazendo mitos e redesenhando roteiros. Brasília: Enap, 2000. (Cadernos Enap, n. 20).

DRUCKER, Peter. O surgimento da nova administração. In: CHAMPY, James; NOHRIA, Nitin. Avanço rápido: as melhores idéias sobre o gerenciamento de mudanças nos negócios. Rio de Janeiro: Campus, 1997.

FELDMAN, Martha S.; KHADEMIAN, Anne M. To manage is to govern. Public Administration Review, v. 62, n. 5, Sept./Oct. 2002.

GARCES, Ariel; SILVEIRA, José Paulo. Gestão pública orientada para resultados no Brasil. Revista do Serviço Público, v. 53, n. 4, out./dez. 2002.

GIL, A. C. Métodos e técnicas de pesquisa social. 5. ed. São Paulo: Atlas, 1999.

HERSEY, Paul; BLANCHARD, Kenneth H. Psicologia para administradores: a teoria e as técnicas da liderança situacional. São Paulo: EPU, 1986.

LEWIS, Gregory B.; FRANK, Sue A. Who wants to work for the government? Public Administration Review, v. 62, n. 4, July/Aug. 2002.

MARINI, Caio. O contexto contemporâneo da administração pública na América Latina. Revista do Serviço Público, v. 53, n. 4, out./dez. 2002.

OLIVEIRA, Djalma de Pinho Rebouças. Sistemas, organização e métodos: uma abordagem gerencial. 13. ed. São Paulo: Atlas, 2002. 
OLIVEIRA, Ricardo de. O processo de modernização do Inmetro: relato de uma experiência. Revista do Serviço Público, v. 53, n. 4, out./dez. 2002.

OSBORNE, David; GAEBLER, Ted. Reinventando o governo: como o espírito empreendedor está transformando o setor público. 10. ed. Brasília: MH Comunicação, 1998.

O’TOOLE, James. Liderando mudanças: como superar a ideologia do conforto e a tirania do costume. São Paulo: Makron Books, 1997.

PACHECO, Regina Silva. Política de recursos humanos para a reforma gerencial: realizações do período 1995-2002. Revista do Serviço Público, v. 53, n. 4, out./dez. 2002.

RAMOS, Guerreiro. Administração e estratégia do desenvolvimento: elementos de uma sociologia especial da administração. Rio de Janeiro: FGV, 1966.

ROBBINS, Stephen P. Comportamento organizacional. 8. ed. Rio de Janeiro: LTC, 1999.

ROSENBERG, Gerson; OHAYON, Pierre. Auto-avaliação da gestão em organizações públicas de ciência e tecnologia: um instrumento aplicado à Fiocruz — Fundação Oswaldo Cruz. In: ENCONTRO ANUAL DA ANPAD, 25., Salvador, 2002. Anais... Salvador: Anpad, 2002.

SCHERMERHORN JR., John R.; HUNT, James G.; OSBORN, Richard N. Fundamentos de comportamento organizacional. 2. ed. Porto Alegre: Bookman, 1999.

SILVEIRA, A. E. L.; AGUINSKY, B. G. Desjudicialização e municipalização do atendimento das medidas sócio-educativas de meio aberto: a experiência da $3^{\text {a }}$ Vara do Juizado Regional da Infância e Juventude de Porto Alegre. Porto Alegre: Poder Judiciário do Estado do Rio Grande do Sul, 2003. (Relatório Técnico da $3^{\mathfrak{a}}$ Vara JIJ).

TACHIZAWA, Takeshi; SCAICO, Oswaldo. Organização flexível. São Paulo: Atlas, 1997.

VIEIRA, Eleonora Milano Falcão. Análise da informação em sistemas protocolares. Disponível em: <www.ajuris.org/experienciadocente/impactosocialdati/isti.asp/biblioteca/ artigoeleonora.pdf > . Acesso em: 26 nov. 2003. 